\title{
Editorial
}

\section{Neuroscience and subjectivity}

\author{
Subjectivity (2011) 4, 215-226. doi:10.1057/sub.2011.13
}

As we write there are spectacular uprisings all across the Middle East, and angry responses to public spending cuts and attacks on worker's pensions, pay and conditions in Greece, Portugal, Ireland, the United Kingdom and France. So this might seem like a strange time to be focusing attention 'inward', on the workings of the brain: at such a moment, interest may be drawn to wider social, economic and cultural forces and the ways that their shifting contingencies intersect to produce radical - or indeed, conservative subjectivities. Nevertheless, as the papers in this special issue show, such considerations remain vital. On the one hand they might enliven social science, giving it a robust, intimate grasp upon some of the embodied, material processes by which all subjectivities - both conservative and radical - are inculcated and enabled. And on the other, they demonstrate the continuing importance of the social sciences and humanities at a time when - in the United Kingdom, at least - their existence appears threatened as never before.

The contemporary neurosciences form an influential and complex matrix of interdependent practices, technologies, methods and theories, whose efforts are jointly directed towards a better understanding of one of the most extraordinary objects in the known universe: the human brain. In recent years they have benefitted from a powerful infusion of funding, and initiatives such as the 1990's 'Decade of the Brain' have generated a massive boom in knowledge and practice. As it has expanded, the field has divided into primary regions of cognitive, social and affective neuroscience, with numerous smaller (and frequently applied) sub-disciplines cross-cutting these. Simultaneously, the various brain imaging technologies (MRI, fMRI, PET, MEG, fNIRS), with their seeming ability to visualise living thought itself, have done much to capture the public imagination. As the following examples illustrate, a cultural climate has emerged within which neural tropes, brain imaginaries and (more rarely) established facts are mobilised to inform social policy, legitimate clinical interventions and refashion existing bodies of thought and practice for a new era of supposed 'brainhood' (see, for example, Vidal, 2009; Ortega and Vidal, 2010; Royal Society, 2011). 
Example one: in 2007, the best-selling author, psychiatrist and psychoanalyst Norman Doidge publishes, to critical acclaim, The Brain that Changes Itself: Stories of Personal Triumph from the Frontiers of Brain Science (Doidge, 2007). Drawing upon the recent science of 'neuroplasticity', Doidge offers stories of the plasticity of our senses, of how stroke victims learn to move and speak again and so on - and other arguments and insights pertaining inter alia to the 'culturally modified brain', the notion of 'plasticity as progress', even the suggestion of 'psychoanalysis as a neuroplastic therapy'. Here we are invited not simply to consider the manner in which these findings are challenging or overturning old ways of thinking about the brain, but to celebrate the awesome 'self-healing power that lies within all of us'. Part and parcel of wider sociocultural tropes and trends towards complexity, flexibility, enterprise and enhancement in all spheres of life, the book in this respect is very much a product of its times, reflecting and reinforcing both neoliberal and neurocultural themes and imperatives.

Example two: another popular book, Proust Was a Neuroscientist (Lehrer, 2011), argues that many neuroscientific discoveries are in fact re-discoveries of insights already achieved by great artists: by Proust with regard to the fallible, reconstructive character of memory, by Cézanne with regard to vision, by Whitman with regard to the biological substrates of consciousness, and so on. Here, neuroscience and art continuously rebound such that each affirms the other, and the historic divide between the 'two cultures' is optimistically disregarded: neuroscience is playing 'catch up' with art, art is being enriched by neuroscience. In largely ignoring the profound differences between these disparate communities of practice, Lehrer's relatively thin work has the potential to alienate them all, and its advocacy of art as a distinct mode of cognition merely echoes Langer's (1967) earlier important work. Its popularity, nevertheless, illustrates the 'seductive allure' (Fine, 2010) of contemporary neuroscience.

Example three: in 2009, Professor David Nutt was fired as Chief Scientific Adviser on UK government drugs policy after publicly claiming that this advice was being disregarded by politicians. Early in 2011, he attracted further media attention for his claims that the spending cuts and funding changes being implemented by the current UK government are the 'last nail in the coffin' of UK basic neuroscientific research (BBC, 2011). Almost simultaneously, UK news excitedly reported research that supposedly identified a brain region (the medial prefrontal cortex) where heroin 'relapse' occurs (Bossert et al, 2011) - albeit that the study participants were rats. A few months earlier, the journal Biosocieties presented an excellent special issue on neuroscience and drug dependency that served to situate all such claims with respect to the historical, cultural and material contexts within which drug dependency actually arises (Dunbar et al, 2010). Marred only by a sometimes uncritical acceptance of the concept of addiction (as though this were an observable brain state or objective 
social fact, rather than a loose term linking disparate activities to negative moral judgements), the contributors gave a thorough account of the neuroscience of drug dependency that was constantly referred back to its own genealogy and institutional history and located within social and political economies of (for example) ethnicity and class.

These examples begin to illustrate how the cultural uptake of neuroscience is contingent and variable, both impeded and progressed by the intersecting tensions generated by material, institutional and intellectual forces. Doidge and Lehrer show that neuroscience is explicating how the malleable processes of experience are enabled, neurally, by the plasticity of dendrite and synapse, the fluctuations of peptide, hormone and neurotransmitter. Conversely, neuroscientific accounts of drug dependency suggest that processes of 'addiction' are locked into place by neuroanatomies so stable that they can be characterised as a chronic brain disorder (Kuhar, 2010). Doidge uses neuroscience to celebrate a view of subjectivity that fundamentally accords with neoliberal precepts of choice, flexibility, self-care and personal responsibility (Maasen and Sutter, 2007; Pitts-Taylor, 2010). Conversely, Nutt uses neuroscience to critique other aspects of this same neoliberal agenda, legitimating arguments for more generous state funding of research and against the criminalisation of (some) recreational drugs.

Similar contradictions appear when we consider the relations between neuroscience and other disciplines. Lehrer - and indeed other more serious writers show how neuroscience is rejuvenating aspects of the humanities and the social sciences, lending new credibility to ideas and practices from the arts and psychotherapy, informing conceptual development in relation to selfhood, agency and morality, and providing rich material for studies in history, STS, political economy and other disciplines. Conversely, neuroscience also threatens to colonise or even engulf some disciplines. This threat is perhaps clearest in psychology, where those sub-disciplines most able to surf the neural wave are growing in prestige and size (Marshall, 2004). But developments such as social neuroscience also raise important questions for sociology, particularly in the context of a more general 're-biologisation of the social world', both within and beyond the neurosciences (Fuller, 2006). Consequently, neuroscience provides challenges that might de-stabilise existing regimes of power by demonstrating and elucidating the thoroughly socio-neural character of experience: but it also provides both armour and ammunition for retrograde tendencies seeking to further marginalise progressive thought and practice.

Analysts frequently argue that there has recently been a marked transformation in the cultural significance of the neurosciences, consequent upon and bound up with changes in the disciplines themselves; Abi-Rached and Rose (2010), for example, identify the rise of the 'neuromolecular' gaze in the 1960s as a critical moment. It is argued that these changes have together promulgated a flattening of subjectivity, and a distinct shift from a psychological to a 
biological regulatory discourse (Rose, 2005). Elsewhere in the humanities and social sciences, scholars are embracing more of the embodied and material dimensions of subjectivity: both the turn to affect and the rise of process philosophy are serving to inform, and to some extent mutate, longstanding interests in emotion, bodies, materiality, performance and practice. Moreover, forms of 'biosocial' thinking, as Fuller (2006) rightly reminds us, are themselves not entirely new or novel. The elision of biological and sociological concerns dates back to the classics (viz. Marx, Durkheim, Weber, Simmel and Parsons) and is part and parcel of the 'hidden biological past of social theory' (see also Turner, 2007). So, while the neurosciences are fostering change, there are also elements of continuity and return, albeit that these arise in new contexts and circumstances.

The striking proliferation of new 'neuro' sub-disciplines (neuropsychoanalysis, neuropolitics, neuroethics, neuroleadership, neuromarketing and so on) nevertheless illustrates how the practices and findings of neuroscience are getting woven into the fabric of everyday life: through their circulation in media and discourse, and by their shaping of institutions and practices, they promise to refashion subjectivity. Yet there remains a gulf between what neuroscience can achieve and what is claimed on its behalf, a distance between what it actually shows and what it perhaps seems to offer. And it is not only scholars in the humanities and social sciences who recognise this: many neuroscientists themselves bemoan the damage wrought by 'neuromyths' that oversell their work (for example, Goswami, 2004). However, some neuroscientists do collaborate with media, drug companies and other institutions to promulgate versions of their work that negate the extent to which both the functions and structure of the brain are experience-dependent and socially enrolled.

Consequently, many in the social sciences and humanities are sceptical of the hype associated with neuroscience and its application. As Ray Tallis notes, 'hardly a day passes without yet another breathless declaration in the popular press about the relevance of neuroscientific findings to everyday life' (Tallis, 2009). Such declarations frequently proclaim a new 'hard science', 'objective' or 'real' understanding of ourselves (that was somehow hitherto lacking), claims that are frequently challenged on closer examination. As it is when neuroscience is actually applied that the accuracy of such claims comes to matter most, we will now consider a fourth example: the application of neuroimaging to lie detection.

This topic deserves critical attention because of the intense military and intelligence services interest it now attracts: since 2001 'connections to the US government, Homeland Security, and the military abound in brain-based detection research' (Littlefield, 2009, p. 370). Lawrence Farwell, founder of Brain Fingerprinting Laboratories, argues that neuroimaging techniques 'can distinguish between the trained terrorist and the innocent international student' (Littlefield, 2009, p. 381; cf. Cavuoto, 2003). As Littlefield observes, this 
kind of research not only interprets deception 'as a sign of biological deviance' (2009, p. 367) but also constructs it as a vital concern to terrorism and military security. Given these concerns, it is of particular interest to ask whether neuroimaging can objectively establish whether someone is lying. Can the complexity of our social, psychological and biological lives really be reduced to a single neurological measure? A careful reading of the evidence suggests that the answer is 'No'.

First, most of the research demonstrating the efficacy of neuroimaging for lie detection involves laboratory studies. The only published field study reported approximately chance accuracy (Miyake et al, 1993), suggesting that the efficacy of neuroimaging in lie detection is highly context-dependent and may not transcend the contrived setting of the laboratory. Second, a recent experiment showed that people can very easily use 'faking strategies' to conceal lies (Ganis et al, 2011). Participants in an imaging study were asked to indicate whether they recognised a variety of mostly random dates; however, one of the dates was their own birthday, and they were instructed to lie about recognising this date. In one experimental condition, the participants were also told to make imperceptible finger and toe movements throughout the task, and the study indicated that these movements effectively masked any heightened neurological response to the perception of their own birthdate. Ganis et al (2011) note that their findings directly question the reliability of neuroimaging in courtroom cases, as similar strategies could be used by defendants.

So neuroscience cannot necessarily provide 'hard', context-free 'objective' or universal analysis: a point of particular salience and significance in terms of current debates about the effects of so-called 'cognitive enhancement' drugs among the healthy, which all too frequently and unproblematically extrapolate from test results found in the controlled settings of laboratory or clinic to the complex layers and relays of everyday life. As with existing psychophysiological research, neurological assessment is continuously influenced by the physical, social and psychological context in which it is undertaken (Newton, 2003, 2007; Littlefield, 2009) - an irreducible complexity that involves the neural, the cardiovascular and the neuroendocrinal, all of these simultaneously both enabling and interpenetrated by the massively fluctuating and interwoven diversities of our psychosocial processes and socio-cultural contexts (Elias, 1994).

Consequently, the neurosciences generate both problems and potentials for studies of subjectivity. Many of the seeming potentials of neuroscience flow from the revelations of fine-grained neural plasticity that brain imaging reveals: while the gross structure of the brain exhibits significant degrees of genetic control, the fine structure of neural networks linking within and across its regions increasingly appears to be experience-dependent and capable of substantial modification. Notwithstanding that the potentials of plasticity can also be recuperated for neoliberalism, its extent and nature casts further doubt 
over accounts of phenomena - such as drug dependency (for example, Kuhar, 2010) and the so-called mental illnesses (for example, Cromby and Harper, 2009; Martin, 2010) - that portray them as 'simply' neural. Plasticity of course has limits: evidence from trauma and stroke patients (see Kleim and Jones, 2008) shows that despite significant experience-dependent effects, wholesale neural reconstruction of the adult human brain does not occur. Plasticity nevertheless provides both arguments and evidence for accounts of subjectivity that can neither be 'read off' from the neural nor understood thoroughly in its absence.

Plasticity apart, neuroscience can generate accounts that minimise moral accountability, by transferring agency and culpability from conscious self to a-conscious brain processes. Claims for this kind of shift sometimes appear within basic neuroscientific research, as in the refiguring of drug dependency as a brain disorder that, once acquired, lays its possessor constantly open to relapses that are not so much failures of will and courage as effects of morally blind neural systems (Campbell, 2010). Similar attributions may also be deployed in lay contexts where the links to basic research are arguably more tenuous. For example, they are now seen as functional in some schools of psychotherapy, where progress can be attributed to courage and effort while problems are attributed to implicit memory or affect systems out with conscious control (Lipchik et al, 2005). Ultimately, of course, this is a double-edged sword: although individuals are not accountable and cannot be blamed, they simultaneously cannot wholly control themselves and must accept the consequences.

Relatively stable brain characteristics can also enable progressive arguments, as with discussions of research demonstrating the existence of a human mirror neuron system (Mukamel et al, 2010). This system consists of neurons that fire both when certain actions are performed and when we see others perform them, and so purportedly allows quasi-direct, pre-reflective access to the embodied states of others. Olson (2009) uses this evidence to naturalise empathy, community and regard for others as intrinsic to our species-nature, so highlighting the ideological work of adverse socialisation needed to inculcate the selective regard and competitive callousness required by capitalism. Nevertheless, here too we must remain cautious. As Vivona (2009) notes, the 'mirror' metaphor conceals the context-dependency of these neural firings, and evidence for actual mirroring of affective states is largely absent and, where it exists, contradictory. Even so, mirror neurons can foster progressive political potentials, albeit that these come at the cost of essentialising a neural process. Mirror neurons might also be seen as offering a putative material basis for the forms of suggestibility, affective contagion and attunement being explored within the affective turn (Brennan, 2004).

Despite these potentials, the neurosciences can still unleash the interdependent problems of essentialism, determinism, decontextualism and reductionism. 
Again, there are important nuances here: many neuroscientists themselves are now more aware of these problems, and social scientists sometimes deploy selfserving caricatures that promote just the kinds of disciplinary imperialism to which they themselves rightly object (Williams, 2001, 2003, 2006). But there undoubtedly are significant difficulties in some quarters, perhaps especially - as in the case of phenomena related to psychiatry, for example - where such conceptual moves can serve wider interests of commerce and power. Moreover, as the European Neuroscience and Society Network website argues, we may yet see the rise of 'new forms' of reductionism and determinism, new manifestations of old problems, produced through the cultural uptake of new and complex technologies and findings.

The novelty of the problems associated with the contemporary neurosciences is emphasised by Bennett and Hacker (2003) who describe them as inflected with a 'mutant' or 'degenerate' version of Cartesian dualism, within which psychological predicates previously ascribed to the mind (rather than the human being) are now ascribed to the brain. In their analysis, this is not just a form of dualism: it is also a profound conceptual error that undermines many contemporary neuroscientific claims. Although Bennett and Hacker's work can be challenged (for example, Janzen, 2008), it finds echoes in other critiques: Vivona's (2009) penetrating analysis of the claims made for mirror neurons, for example, proceeds in a similar fashion to theirs but without invoking their Wittgensteinian framework. Moreover, even within social neuroscience - the sub-discipline most obviously open to social scientific collaboration - the adherence to methodological procedures from experimental psychology reproduces individualist assumptions within the very practice of research, meaning that its account of social and cultural influence will always be partial (Cromby, 2007). Hence in a detailed analysis of the contribution of neuroscience to the affective turn, Papoulias and Callard (2010) acknowledge that neuroscience might have something to contribute but also raise many cautionary points.

In short, the neurosciences are likely to continue occupying a contradictory position in relation to humanities and social science studies of subjectivity. At the worst, their capacity to colonise, reduce and dismiss the richness of explanatory detail that the social sciences and humanities work with will continue to disturb and repel. But the neurosciences might also offer insights that enrich our understandings of the ways in which cultural, social and material influence actually get made flesh, and hence of the ways in which the enculturated brain and body subtend and enable not simply subjectivity but intersubjectivity (Franks, 2010).

The contributors to this special issue discuss the contemporary neurosciences in relation to a range of substantive concerns that bear upon the constitution of subjectivities. Their insightful, scholarly contributions mobilise insights and concepts from social theory, philosophy, feminism, sociology and other disciplines, using these both to explicate the assumptions inherent in 
neuroscientific claims and to reflect upon humanities and social science engagements with neuroscience. While their analyses are multi-faceted and can fruitfully be read in many different ways, we have organised them here in relation to three relevant questions.

First: What and where are the neural mechanisms that enable subjectivity? In the future, it seems, many neuroscientists might suggest that they reside largely in the recently discovered default mode network (DMN). In a rare example of direct collaboration between a neuroscientist and a social scientist, Felicity Callard and Daniel Margulies's paper The Subject at Rest: novel conceptualisation of self and brain from cognitive neuroscience's study of the resting state describes how a decade or so of brain imaging research has led to the discovery of a system of neural circuits that seem to be consistently active - both when people are completing requested tasks, and when they are resting. Neuroscientists suggest that this DMN enables 'self referential mental activity' and representations that 'embody aspects of self'. Its discovery is described as heralding a 'paradigm shift' wherein research might begin to focus as much on the brain's autopoietic activity as on the reflexive neural activity interpellated by environmental stimuli (and which provides the conceptual basis for the plethora of research claiming that 'brain region $\mathrm{x}$ is the basis of ability y').

Callard and Margulies suggest that the DMN might well spark a new wave of interest in the implications of neuroscience, and point to the recent appearance of a spate of popular articles discussing its significances. Nevertheless, the analysis by Clifford van Ommen and Vasi van Deventer of an earlier attempt to locate the integrative and agentic aspects of subjectivity within a specific brain region suggests that we might do well to remain cautious of such claims. Their paper The economy of centre within the aneconomy of neural architecture offers a close, critical reading of Goldberg's work in which he identifies the prefrontal cortices as the dominant locus of the 'executive functions' of the brain. They place all such claims in a historical lineage that has seen the 'seat of the soul' shift from one ventricle to another, one brain system or region to the next. Simultaneously, their Derridean analysis troubles the notion of 'presence' underlying any claim to have identified an essential centre in the massively complex ensemble of multiple, parallel and overlapping networks that constitute the living brain.

Second: How is or should the neural be figured in relation to the social? It is increasingly clear that the brain is a dynamic, open system: the more we look inside it, the more our attention rebounds to the social, material and environmental influences that - in simultaneous concert with its own autopoietic mechanisms - maintain its homeodynamic status. This suggests that the presumed certainties of neuroscience must frequently yield to much more nuanced and variable accounts of causation, enabling and association. These accounts undo taken-for-granted understandings of the relation between neural and 
social, while simultaneously revealing the assumptions upon which orthodox claims necessarily rest.

Elizabeth Wilson demonstrates this in her close analysis of selective serotonin reuptake inhibitors (SSRIs - most famously, Prozac) and childhood depressive states. Her paper Neurological entanglements: The case of pediatric depressions, SSRIs and suicidal ideation builds upon her recent influential work exploring the ways in which research into the enteric nervous system in the gut can be used to generate novel accounts of subjective states, including those associated with a diagnosis of depression (Wilson, 2004). Wilson's analysis of the associations between SSRIs and childhood misery draws upon Barad's work and treats these drugs as elements of a system that includes 'pill, neuron, synapse, mood, psyche, subcortical pathway, chemical, economy, institution, discourse'. Her analysis demonstrates how the chemical, the neural and the affective are always already thoroughly implicated, each within the other, such that what are ostensibly solely pharmaceutical interventions are always simultaneously both less and more than this.

Wilson is interested in the ways that philosophies of the body and theories of the mind inform thinking about both childhood misery and its treatment. In Philosophical Implications of Neuroscience: The space for a critique related concerns are picked up by Maurizio Meloni, who elucidates some of the ways in which philosophical enquiry might lead us to question strong neuroscientific claims. Meloni locates the contemporary prominence of neuroscience in a historical context where the 'ideological failures' of the twentieth century provide a somewhat despairing and ultimately futile impetus for the mobilisation of neural explanations. He reviews scholarly literature in philosophy, cultural theory, feminism, politics and sociology, linking the 'neural turn' within each to growing dissatisfaction with weak versions of constructionism that seem unable to move beyond analyses of knowledge and representation. Meloni argues for resistances and 'spaces of criticism' within which to reflect upon and challenge neuroscientific claims to understand subjectivity, supporting his argument with summaries of philosophical works that mount conceptual, societal and embodied-enactive challenges to simplistic neural explanations.

Third: How are tropes and metaphors from neuroscience already informing the subjectivities we are able to become? Exploring this question, Suparna Choudhury and Francisco Ortega's Wired up differently: Autism, adolescence and the politics of neurological identities compares and contrasts the selfpresentational and identity discourses mobilised by adolescents, and by adults given a diagnosis of autism. Their analysis shows how, among those who are diagnosed, the term autistic is sometimes used deliberately and with 'autistic pride', derived from a folk neurology that insists that the brains of people so described are 'wired up differently' to and better than the brains of others - to whom they refer, in suitably dismissive terms, as the 'Neurologically Typical'. Choudhury and Ortega suggest that these discursive moves come at some cost, 
as they encourage the 'dark side' of identity politics and work against the progressive notions of 'neurodiversity' promulgated by other activists. Moreover, they contrast sharply with the talk of adolescents, within which there was a consistent commitment to the notion that subjectivity is shaped by experience.

In their paper Constituting neurolgic subjects: Neuroscience, subjectivity and the mundane significances of the brain, Martyn Pickersgill, Sarah BurleyCunningham and Paul Martin report a complementary study analysing focus group discussions consisting of neurological patients; professionals such as teachers and care workers, for whom neuroscientific claims might have particular resonance; and neuroscientists themselves. Their findings question the extent to which we are simply becoming 'neurochemical selves', suggesting instead that neural understandings are being layered upon or mobilised flexibly alongside older, established ways of constructing identity and selfhood: for the most part, the people in their focus groups continued to understand themselves as hybrid subjects rather than exclusively or primarily neurological ones. At the same time, like Choudhury and Ortega's analysis their study also points to more profound questions regarding the extent to which neuroscience might contribute to regulatory mechanisms that lock into place discursive, social, legal and material practices, organised by and enactive of distal power relations, which greatly exceed the everyday identity choices we are able to make.

To conclude: in their various ways, all of the papers in this special issue take seriously the notion that contemporary neuroscience is relevant to subjectivity. In so doing, they challenge attempts to simply locate subjectivity 'inside' the body, very effectively problematising tendencies that might treat it as separate from the social and rendered exclusively by the neural. It remains difficult to isolate the biological from the social, as the two continuously interpenetrate (Elias, 1991; Shilling, 1993/2003; Williams et al, 2003; Williams, 2006; Newton, 2007; Cromby and Harper, 2009). It is also the case that in interrogating the neuroworld, we must proceed with caution, given the possibility that it will reinforce regressive, reductionist or neoliberal conceptions of ourselves (Pitts-Taylor, 2010). Yet at the same time, to dismiss the neurological is to retreat to the comfort zone of familiar dualist schisms.

\section{References}

Abi-Rached, J. and Rose, N. (2010) The birth of the neuromolecular gaze. History of the Human Sciences 23(1): 11-26.

BBC. (2011) Neuroscience cuts 'the last nail in the coffin', http://news.bbc.co.uk/today/hi/ today/newsid_9394000/9394163.stm, accessed 11 April 2001.

Bennett, M.R. and Hacker, P.M.S. (2003) Philosophical Foundations of Neuroscience. Oxford: Blackwell. 
Bossert, J. et al (2011) Ventral medial prefrontal cortex neuronal ensembles mediate context-induced relapse to heroin. Nature Neuroscience 14: 420-422.

Brennan, T. (2004) The Transmission of Affect. Ithaca, NY: Cornell University Press.

Campbell, N. (2010) Toward a critical neuroscience of 'addiction'. Biosocieties 5: 89-104.

Cavuoto, J. (2003) Brainwave Sensor Touted as Tool in Counter-terrorism. Neurotech Business Report, www.neurotechreports.com/pages/brainfingerprinting.html, accessed 12 April 2011.

Cromby, J. (2007) Integrating social science with neuroscience: Potentials and problems. Biosocieties 2(2): 149-170.

Cromby, J. and Harper, D. (2009) Paranoia: A social account. Theory and Psychology 19(3): 335-361.

Doidge, N. (2007) The Brain that Changes Itself: Stories of Personal Triumph from the Frontiers of Brain Science. Harlow, UK: Penguin.

Dunbar, D., Kushner, H. and Vrecko, S. (2010) Drugs, addiction and society. Biosocieties 5: 2-7.

Elias, N. (1991) The Symbol Theory. London: Sage.

Elias, N. (1994) The Civilizing Process. Oxford: Blackwell.

Fine, C. (2010) Delusions of Gender: The Real Science behind Sex Differences. London: Icon.

Franks, D. (2010) Neurosociology: The Nexus between Neuroscience and Social Psychology. New York; London: Springer.

Fuller, S. (2006) The Sociological Imagination. London: Sage.

Ganis, G., Rosenfeld, J., Meixner, J., Kievit, R. and Schendan, H. (2011) Lying in the scanner: Covert countermeasures disrupt deception detection by functional magnetic resonance imaging. Neuroimage 55: 312-319.

Goswami, U. (2004) Neuroscience and education. British Journal of Educational Psychology 74: 1-14.

Janzen, G. (2008) Bennett and hacker on neural materialism. Acta Analytica 23(3): 273-286.

Kleim, J. and Jones, T. (2008) Principles of experience-dependent neural plasticity: Implications for rehabilitation after brain damage. Journal of Speech, Language and Hearing Research 51: s225-s239.

Kuhar, M. (2010) Contributions of basic science to understanding addiction. Biosocieties 5: $25-35$.

Langer, S. (1967) Mind: An Essay on Human Feeling, Vol. 1. Baltimore, MD: The Johns Hopkins University Press.

Lehrer, J. (2011) Proust was a Neuroscientist. Edinburgh, UK: Canongate Books.

Lipchik, E., Becker, M., Brasher, B., Derks, J. and Volkmann, J. (2005) Neuroscience: A new direction for solution-focused thinkers? Journal of Systemic Therapies 24(3): 49-69.

Littlefield, M. (2009) Constructing the organ of deceit: The rhetoric of fMRI and brain fingerprinting in post-9/11 America. Science Technology and Human Values 34(3): 365-392.

Maasen, S. and Sutter, B. (2007) On Willing Selves: Neoliberal Politics and the Challenge of Neuroscience. Basingstoke, UK: Macmillan.

Marshall, P. (2004) Relating psychology and neuroscience: Taking up the challenges. Perspectives on Psychological Science 4(2): 113-125.

Martin, E. (2010) Self-making and the brain. Subjectivity 3(4): 366-381.

Miyake, Y., Mizutanti, M. and Yamahura, T. (1993) Event related potentials as an indicator of detecting information in field polygraph examinations. Polygraph 22: 131-149. 
Mukamel, R., Ekstrom, A., Kaplan, J., Iacoboni, M. and Fried, I. (2010) Single neuron responses in humans during execution and observation of actions. Current Biology 20: $750-756$.

Newton, T.J. (2003) Truly embodied sociology: Marrying the social and the biological? The Sociological Review 51(1): 20-42.

Newton, T.J. (2007) Nature and Sociology. London: Routledge.

Olson, G. (2009) Empathy and neuropolitics. This is your brain on neoliberal culture: Any questions? http://home.moravian.edu/public/polsci/olson.htm, accessed 11 April 2011.

Ortega, F. and Vidal, F. (eds.) (2010) Neurocultures. Pieterlen, Switzerland: Peter Lang.

Papoulias, C. and Callard, F. (2010) Biology's gift: Interrogating the turn to affect. Body and Society 16(1): 29-56.

Pitts-Taylor, V. (2010) The plastic brain: Neoliberalism and the neuronal self. Health 14(6): 635-652.

Rose, N. (2005) Becoming neurochemical selves, http://www.lse.ac.uk/collections/sociology/ pdf/Rose-BecomingNeurochemicalSelves.pdf, accessed 4 December 2006.

Royal Society. (2011) Brainwaves, http://royalsociety.org/brainwaves/, accessed 11 April 2011.

Shilling, C. (1993/2003) The Body and Social Theory, 1st/2nd edn. London: Sage.

Tallis, R. (2009) Neurotrash. New Humanist 124(6), http://newhumanist.org.uk/2172/ neurotrash, accessed 25 May 2011.

Turner, S. (2007) Social theory as cognitive neuroscience. European Journal of Social Theory 10(3): 357-373.

Vidal, F. (2009) Brainhood, anthropological figure of modernity. History of the Human Sciences 22(1): 5-36.

Vivona, J. (2009) Leaping from brain to mind: A critique of mirror neuron explanations of countertransference. Journal of the American Psychoanalytic Association 57: 525-550.

Williams, S.J. (2001) Sociological imperialism and profession of medicine revisited. Sociology of Health of Illness 23(2): 135-158.

Williams, S.J. (2003) Medicine and the Body. London: Sage.

Williams, S.J. (2006) Medical sociology and the biological body: Where are we now. Health: An Interdisciplinary Journal for the Social Study of Health, Illness and Medicine 10(1): 5-30.

Williams, S.J., Birke, L. and Bendelow, G. (2003) Debating Biology. London: Routledge.

Wilson, E.A. (2004) Psychosomatic: Feminism and the Neurological Body. Durham, NC; London: Duke University Press.

John Cromby

Loughborough University, Leicestershire, UK.

E-mail: J.Cromby@lboro.ac.uk

Tim Newton

Simon J. Williams

Department of Sociology, University of Warwick, UK. 